\title{
A Time-Varying Coupling Analysis of Expressway Traffic Volume and Manufacturing PMI
}

\author{
Shuo Sun $\mathbb{D}^{1},{ }^{1,2}$ Mingchen Gu, ${ }^{1,2}$ Yingping Wang, ${ }^{1,2}$ Rongjie Lin, ${ }^{1}$ Lifeng Xing, \\ and Zhiyuan $\mathrm{Xu}^{1,2}$ \\ ${ }^{1}$ Transport Planning and Research Institute, Ministry of Transport, Beijing 100028, China \\ ${ }^{2}$ Laboratory for Traffic \& Transport Planning Digitalization, Beijing 100028, China \\ Correspondence should be addressed to Shuo Sun; sunshuo@tpri.org.cn
}

Received 3 August 2020; Revised 3 October 2020; Accepted 3 August 2021; Published 20 August 2021

Academic Editor: Francesco Viti

Copyright (c) 2021 Shuo Sun et al. This is an open access article distributed under the Creative Commons Attribution License, which permits unrestricted use, distribution, and reproduction in any medium, provided the original work is properly cited.

\begin{abstract}
This study investigates the time-varying coupling relationship between expressway traffic volume and manufacturing purchasing manager index (PMI). First, for the traffic volume and manufacturing PMI time-series data, unit root stability test and Johansen cointegration test are applied to determine the stability of single sequence and the long-term stable correlation between variables, respectively. Then, a time-varying vector autoregressive model (TVP-VAR) is developed to quantify the time-varying correlation between variables. The time-varying parameters of TVP-VAR are estimated using the Markov chain Monte Carlo (MCMC) theory. Finally, the model is validated using examples from China. In the numeric example, three variables, i.e., expressway car traffic volume, expressway truck traffic volume, and manufacturing PMI, are selected for analysis. Results show that there is a positive interaction between expressway traffic volume (both car and truck) and manufacturing PMI. Express traffic volume slowly promotes the development of manufacturing industry. However, with the reform policy of road freight structure in China, the promotion effect of truck traffic on manufacturing PMI in the past two years has decreased significantly. Moreover, as affected by the China demand-led economic development model in recent years, the stimulus effect of manufacturing PMI on expressway passenger traffic volume has increased year by year. And, while the expressway freight structure remains stable, truck traffic volume is hardly affected by fluctuations in manufacturing PMI. These research results are helpful for policy makers to understand the time-varying coupling relationship between expressway traffic volume and manufacturing development and finally to improve the expressway management level.
\end{abstract}

\section{Introduction}

Expressway is the critical infrastructure for modern economic and social development and is also the important foundation for the construction of transportation modernization [1-3]. By the end of 2019, the expressway in China reached $149,600 \mathrm{~km}$ in mileage, ranking first in the world. Traffic volume of the section reached 27,000 passenger car unit per day $(\mathrm{pcu} / \mathrm{d})$. The fast-developing process of the expressway has played a positive role in promoting the sustained and rapid growth of manufacturing economy [4]. During the coronavirus pandemic (COVID-19) period in 2020, China's expressway vehicle tolls were waived until May 5 , and under such condition, traffic volume has increased by
$20 \%$ compared with the same period in the last year. Clearly, the increase in traffic has helped the resumption of work and production in economic recovery period. However, existing methods cannot dynamically measure the promotion effect of expressway traffic on manufacturing economy. The mutual relationship between expressway traffic and manufacturing economy needs in-depth study.

In recent years, many researchers have analyzed the impact of expressway on economic development of manufacturing industries. Their results showed a positive impact of expressway capital stock on gross domestic product (GDP) [5]. For example, areas with high traffic mileage have higher manufacturing and employment levels, and there is a positive lagging correlation between road 
attributes and manufacturing [6]. From the perspective of spatial dependence and heterogeneity, the impact of improving transportation infrastructure on manufacturing agglomeration is also positive [7]. Moreover, transportation infrastructure has a typical spatial nonlinear diminishing effect on manufacturing agglomeration [8].

Expressway traffic volume is one of the most important indicators for operation analysis. Many researchers have proved that expressway traffic volume is closely related to GDP growth. Within years, this relationship gradually strengthens $[9,10]$. Results of the cointegration test showed that there is a long-term equilibrium relationship between the freight volume and the output value of primary, secondary, and tertiary industries [11]. These results indicate that expressway traffic volume is strongly related to the development of national economy [12].

Current investigations generally have the following problems. (1) Traffic volumes of private car and truck are not analyzed separately. Current studies only analyze the correlation between overall traffic volume and manufacturing economy. (2) Time-varying characteristics of this relationship are ignored in current studies, despite the relationship between expressway traffic and manufacturing economy changes month by month. (3) Long-term and stable relationships are usually not considered. Therefore, there is an urgent need to investigate the time-varying and long-term effect of expressway traffic on manufacturing economy.

This article applies the time-varying analysis method in econometrics to examine the long-term inter-relationship between time-varying economic index of manufacturing industry and expressway traffic (including private car and truck). The promotion effect of manufacturing activity on expressway traffic, as well as the promotion effect of expressway traffic manufacturing activity, is quantitatively analyzed. Therefore, their long-term mutual promotion effect can be observed. This research is conducive for policy makers to deepen the understanding of social and economic promotion functionality of expressway development.

\section{Methods}

Over the course of modern macroeconomic analysis, the time-varying vector autoregressive model (TVP-VAR) is often used to explore the time-varying interaction of economic variables on macroeconomic issues [13]. The TVPVAR model was originated from the vector autoregressive model (VAR), which is a large-scale simultaneous equation model pioneered by Sims in 1980 [14]. The VAR model can simulate the feedback mechanism between variables when analyzing the relationship between variables. However, the model did not distinguish the specific meaning and variable types of each equation. The VAR model is also constructed based on the lag value of the explained variable and the lag value of other variables. Such facts cause the model to ignore the influence of contemporaneous value of different variables.

Contemporaneous correlation refers to the correlation between the current disturbance term and the explanatory variable. In order to analyze the contemporaneous correlation between variables, Blanchard and Watson [15] constructed a structural vector autoregressive model (SVAR) with structural characteristics. While, in SVAR, the coefficients of equation variables are fixed over time, suggesting that the action mechanism between variables is relatively fixed. This model setting lets the model violate the fact that the actual interaction between variables will fluctuate over time. In recent years, Primiceri [16] proposed a TVP-VAR model with random fluctuations. The model adds timevarying coefficients and variance-covariance matrix to the SVAR model. Thus, the interaction intensity and the timevarying transmission mechanism between variables can be observed. Based on the work of Primicer, Nakajima [17] proposed a set of estimation methods for the TVP-VAR model.

The basic VAR model can be written as

$$
y_{t}=B_{0}+B_{1} y_{t-1}+B_{2} y_{t-2}+\cdots+B_{p} y_{t-p}+u_{t} \text {, }
$$

where $p$ represents the lag order and $t=p+1, p+2, \ldots, n$. $y_{t}, y_{t-1}, \ldots, y_{t-p}$ refer to a set of $k \times 1$ endogenous variables, which are composed of manufacturing PMI and traffic volume of expressway private car and truck. $B_{0}$ is a $k \times 1$ vector of constants, $B_{1}, B_{2}, \ldots, B_{p}$ are coefficient matrices and represent the intertemporal correlation, and $u_{t}$ is the structural shock at time step $t$ and satisfies the following criteria [18]:

$$
\begin{gathered}
E\left(u_{t}\right)=0, \\
E\left(u_{t} u_{t}^{\prime}\right)=\sum_{u}=\left[\begin{array}{cccc}
\sigma_{u 1}^{2} & 0 & \ldots & 0 \\
0 & \sigma_{u 2}^{2} & \ldots & 0 \\
\vdots & \vdots & \ddots & \vdots \\
0 & 0 & \ldots & \sigma_{u k}^{2}
\end{array}\right], \\
E\left(u_{t} u_{\tau}\right)=0, t \neq \tau .
\end{gathered}
$$

Originated from the VAR model, the SVAR model considers the contemporaneous effect between variables in order to capture the variables' instantaneous structural relationship. The SVAR model can be structured as

$$
A y_{t}=B_{0}+B_{1} y_{t-1}+B_{2} y_{t-2}+\cdots+B_{p} y_{t-p}+u_{t},
$$

where $A, B_{1}, \ldots, B_{p}$ are $k \times k$ time-invariant coefficient matrices and represent the intertemporal correlation. $A$ represents the contemporaneous correlation, and $B_{1}, \ldots, B_{p}$ represent the intertemporal correlation. $B_{0}$ is a $k \times 1$ vector of constants.

Generally, $A$ is supposed to be a lower triangular matrix in order to reduce the computational complexity without affecting the inference results:

$$
A=\left[\begin{array}{cccc}
1 & 0 & \ldots & 0 \\
a_{2,1} & \ddots & \ddots & \vdots \\
\vdots & \ddots & \ddots & 0 \\
a_{k, 1} & \ldots & a_{k, k-1} & 1
\end{array}\right] .
$$

SVAR can be converted into the following induced form: 


$$
y_{t}=F_{0}+F_{1} y_{t-1}+F_{2} y_{t-2}+\cdots+F_{p} y_{t-p}+A^{-1} \sum_{u} \varepsilon_{t}, \quad \varepsilon \sim N\left(0, I_{k}\right),
$$

where $F_{i}=A^{-1} B_{i}$, for $i=0,1, \ldots, p . \sum_{u}$ is the disturbance term in the diagonal form. By defining $X_{t}=I_{k} \otimes$ $\left(1, y_{t-1}^{\prime}, \ldots, y_{t-p}^{\prime}\right)$ and $\beta=\left(F_{0}, F_{1}, \ldots, F_{p}\right)^{\prime}$, where $\otimes$ represents Kronecker product, equation (5) can be transformed into

$$
y_{t}=X_{t} \beta+A^{-1} \Sigma_{u} \varepsilon_{t} .
$$

In the SVAR model, coefficients in formula (6) remain unchanged over time. By allowing coefficients and error terms to change over time, SVAR can be extended to the TVP-VAR model:

$$
y_{t}=X_{t} \beta_{t}+A_{t}^{-1} \Sigma_{t} \varepsilon_{t},
$$

where $\beta_{t}, A_{t}$, and $\Sigma_{t}$ are time-varying coefficients. The $k \times$ $(k-1) / 2$ elements in $A_{t}$ can be further stacked into a vector $a_{t}=\left(a_{21, t}, a_{31, t}, a_{32, t}, \ldots, a_{k(n k-1), t}\right)^{\prime}$. Similarly, the diagonal matrix $\Sigma_{t}$ is transformed into a vector $\sigma_{t}=\left(\sigma_{1 t}, \sigma_{2 t}, \ldots, \sigma_{k t}\right)^{\prime}$. Therefore, $h_{t}=\left(h_{1 t}, \ldots\right.$, $\left.h_{k t}\right)^{\prime}$ and $h_{j t}=\ln \sigma_{j t}^{2}$ for $j=1, \ldots, k$. According to the work of Primieri [16], parameters in equation (7) obey the first-order random walk process:

$$
\beta_{t+1}=\beta_{t}+v_{t+1}, a_{t+1}=a_{t}+\varsigma_{t+1}, h_{t+1}=h_{t}+\xi_{t+1},
$$

where $v_{t} \sim N\left(0, \Omega_{\beta}\right), \varsigma_{t} \sim N\left(0, \Omega_{a}\right)$, and $\xi_{t} \sim N\left(0, \Omega_{h}\right)$ are new disturbance items. Under the assumption that coefficients are uncorrelated, the variance-covariance matrix of all perturbations in equation (7) can be written as

$$
V=\operatorname{Var}\left(\left[\begin{array}{c}
\varepsilon_{t} \\
v_{t} \\
\varsigma_{t} \\
\xi_{t}
\end{array}\right]\right)=\left(\begin{array}{cccc}
I_{k} & 0 & 0 & 0 \\
0 & \Omega_{\beta} & 0 & 0 \\
0 & 0 & \Omega_{a} & 0 \\
0 & 0 & 0 & \Omega_{h}
\end{array}\right) .
$$

The above calculation process assumes that the timevarying coefficient follows a first-order random walk process. According to the research of Engle and Watson [19], when an individual receives new information and adjusts the estimation process of equation state, this fluctuation should follow the random Wandering process. Secondly, the random walk process allows the greatest degree of structural parameter changing. This feature allows the TVP-VAR model to capture subtle disturbances. Moreover, the random walk process can reduce the calculation difficulty and the number of calculations, thereby preventing the model from overfitting. Many studies have also proved that the traffic flow variability can be described as a Markov random process with random fluctuations. At the same time, according to the estimation of Primiceri [16], results of the TVP-VAR model are insensitive to assumptions.

For the TVP-VAR model, we use the Markov Chain Monte Carlo (MCMC) method under the Bayesian inference framework to estimate the unknown parameters.
Parameters are first assumed to be constant as in the SVAR model. Then, the least square method is applied to calculate prior initial values of $\beta_{o l s}, a_{o l s}, h_{o l s}, V\left(\beta_{o l s}\right)$, and $V\left(a_{\text {ols }}\right)$. Replace the variance of $h_{\text {ols }}$ with $I_{k}$. Initial values can be obtained as

$$
\begin{aligned}
& \beta_{0} \sim N\left(\beta_{o l s}, 4 V\left(\beta_{o l s}\right)\right), \\
& a_{0} \sim N\left(a_{o l s}, 4 V\left(a_{o l s}\right)\right), \\
& h_{0} \sim N\left(h_{o l s}, 4 I_{k}\right) .
\end{aligned}
$$

The variance part is multiplied by 4 in order to capture more uncertain information and to prevent prior parameter constraints from being too tight.

The hyperparameters are independent of each other and follow inverse-Wishart distributions. Then, according to Primiceri [16], set its prior distribution as follows:

$$
\begin{aligned}
& \Omega_{\beta}^{-1} \sim W\left(1+k_{\beta},\left(\left(r_{\beta}\right)^{2} \cdot\left(1+k_{\beta}\right) \cdot V\left(\beta_{o l s}\right)\right)^{-1}\right), \\
& \Omega_{a}^{-1} \sim W\left(1+k_{a},\left(\left(r_{a}\right)^{2} \cdot\left(1+k_{a}\right) \cdot V\left(a_{o l s}\right)\right)^{-1}\right), \\
& \Omega_{h}^{-1} \sim W\left(1+k_{h},\left(\left(r_{h}\right)^{2} \cdot\left(1+k_{h}\right) \cdot I_{k}\right)^{-1}\right),
\end{aligned}
$$

where $k_{\beta}, k_{a}$, and $k_{h}$ represent the latitude of $\beta_{t}, a_{t}$, and $h_{t}$, respectively. For the $n$-dimensional $p$-order lag SVAR model, compute $k_{\beta}=p k^{2}, \quad k_{a}=k(k-1) / 2$, and $k_{h}=k(k-1) / 2$. In addition, $r_{\beta}, r_{a}$, and $r_{h}$ are set as $0.01,0.1$, and 0.01 , respectively, based on the parameter setting defined by Koop and Korobilis [20].

After obtaining the initial value, divide the parameters of different categories into different parameter blocks so that different parameter blocks have greater independence. Then, sample the conditional posterior of each part, and finally, form the conditional posterior distribution of all parameters. Finally, dynamic parameters of each simultaneous equation in the TVP-VAR model is obtained based on the Monte Carlo simulation technology, in which a balanced distribution of Markov process is constructed.

In order to explain the contemporaneous correlation between variables and to investigate their feedback mechanism, this study uses impulse response to quantify the magnitude of influence between explanatory variables. The impulse response is performed by first fixing perturbations of all other explanatory variables and then allowing the value or the standard deviation of one explanatory variable to deviate one unit from its original value. The newly obtained value of the explanatory variable is called the impulse response [21]. Through impulse response analysis, dynamic influences between unclear variables can be well explained and quantified. The analysis also facilitates the comparison of shock magnitude between variables. The impulse response explains the synchronous correlation between variables and the dynamic influence of lag. Through impulse response function, mutual influences between variables can be quantitatively captured. In the paper, impulse response function is applied to analyze the influence degree between expressway traffic and manufacturing PMI. 


\section{Data Description}

Expressway traffic can be classified into passenger cars (small and medium passenger cars and coaches) and trucks (small trucks, medium trucks, large trucks, extralarge trucks, and containers) according to data collection samples of national expressway. While sensors on some road sections will also collect traffic data about motorcycles and tractors, we consider traffic volume of passenger cars and trucks only since these two types of traffic can intuitively reflect the development of expressways in recent years. Thus, three types of variables, i.e., traffic volume of private cars, traffic volume of trucks, and manufacturing PMI, are analyzed in this paper.

Expressway traffic volumes of passenger cars and trucks are collected by continuously spaced traffic survey stations in the China National Traffic Survey Data Collection System. At present, about 2,200 continuous traffic survey stations are deployed on expressways throughout the country. These traffic survey stations transmit data to the traffic survey system in real time at 5-minute intervals. The data accuracy is over $90 \%$. This paper uses the China National Traffic Survey Data Collection System to extract expressway passenger car and truck traffic volume.

Monthly manufacturing PMI data are obtained from questionnaire surveys of sample companies. The index covers multiple aspects of manufacturing economic activities and has shortest lag period among all macroeconomic series data. Overall, manufacturing PMI reveals the development trend of manufacturing industries in detail. Thus, the index provides an important basis for the country's macroeconomic regulation and guidance of business operations. Generally, the higher the manufacturing PMI, the better the economic trend of manufacturing industry. The department of China National Bureau of Statistics regularly releases the PMI of China's manufacturing industry on the first working day of each month.

In order to analyze the stable and long-term contemporaneous relationship between expressway traffic and PMI, this paper selects expressway passenger car and truck traffic volume and manufacturing PMI data from January 2010 to December 2019 on a monthly basis. It should be noted that the TVP-VAR model explains the interaction between variables by capturing the fluctuations of explanatory variables. Therefore, the dimensionality reduction of data will not affect the calculation results under the condition that the time-series trend remains unchanged. For expressway passenger car and truck traffic volume, divide them by 1000 and take the arithmetic square root. For manufacturing PMI, divide them by 10 and take the arithmetic square root. Figure 1 shows the over-time trend of expressway passenger car and truck traffic volume and manufacturing PMI.

3.1. Data Test. In order to test whether there is a long-term stable correlation between passenger car and truck traffic volume and manufacturing PMI and to ensure that the causal relationship between variables is not a pseudoregression, it is necessary to conduct data stability tests and cointegration relationship tests on the three variables [22].
3.2. Stationarity Test. Stationarity test is to verify whether time series of one variable is stationary. In this paper, the augmented Dickey-Fowler test (ADF) and the unit root test are used to determine the stability of a single variable. Table 1 presents the test results.

The results show that, at 5\% significant level, the original $\mathrm{ADF}$ test values of passenger car traffic, truck traffic, and manufacturing PMI are all greater than the critical value, indicating that the time series of three variables are not stable at the original level. Under the condition of first-order difference, the ADF test values of passenger car traffic, truck traffic, and manufacturing PMI are all less than the critical value at 5\% significant level, suggesting that the time series of three variables are stable. Such result further supports the cointegration relationship test.

3.3. Cointegration Relationship Test. The cointegration relationship test is to verify the long-term correlation between traffic volume (i.e., passenger car and truck) and manufacturing PMI. A VAR model is established for the three variables. Lag order of the three variables is determined to be 1 through the Akaike information criterion (AIC). Table 2 shows the cointegration test results of the three variables under the condition of first-order difference.

Trace and maximum eigenvalue tests in Table 2 shows that the three variables have at most 2 long-term stable correlations when $5 \%$ critical value is considered. Therefore, there is a long-term and stable correlation between passenger car, truck traffic volume, and manufacturing PMI. The test data can be used for TVP-VAR analysis.

\section{Results and Analysis}

The three variables, i.e., traffic volume of expressway passenger car, traffic volume of truck, and manufacturing PMI, are substituted into the TVP-VAR model. C represents expressway passenger car traffic volume. T represents expressway truck traffic volume. $\mathrm{P}$ represents manufacturing PMI index. The lag order is set as $p=1$ according to AIC test results. In impulse response analysis, time lags of 1 month, 2 months, 3 months, and 6 months are considered in order to measure the short-term, midterm, and long-term interactions between variables. In model estimation, least squares algorithm is conducted 4000 times for prior sampling and parameter initialization. Then, 40,000 iterations of Markov chain Monte Carlo simulation are carried out. Figure 2 shows the final calculation result.

Figure 2 shows the time-varying impulse response between the three variables in China from 2010 to 2019 under time lags of 1 month, 2 months, 3 months, and 6 months. In the figure, $x$ - and $y$-axis represent month and the magnitude of impulse response, respectively. A positive impulse response indicates a positive influence between the two variables, while a negative one represents a negative influence relationship. Moreover, the greater the absolute value of impulse response, the more significant the impact. Taking response of $\mathrm{T}$ to $\mathrm{C}$ in Figure 2(b) as an example, the result represents the timevarying influence of expressway passenger car traffic volume 


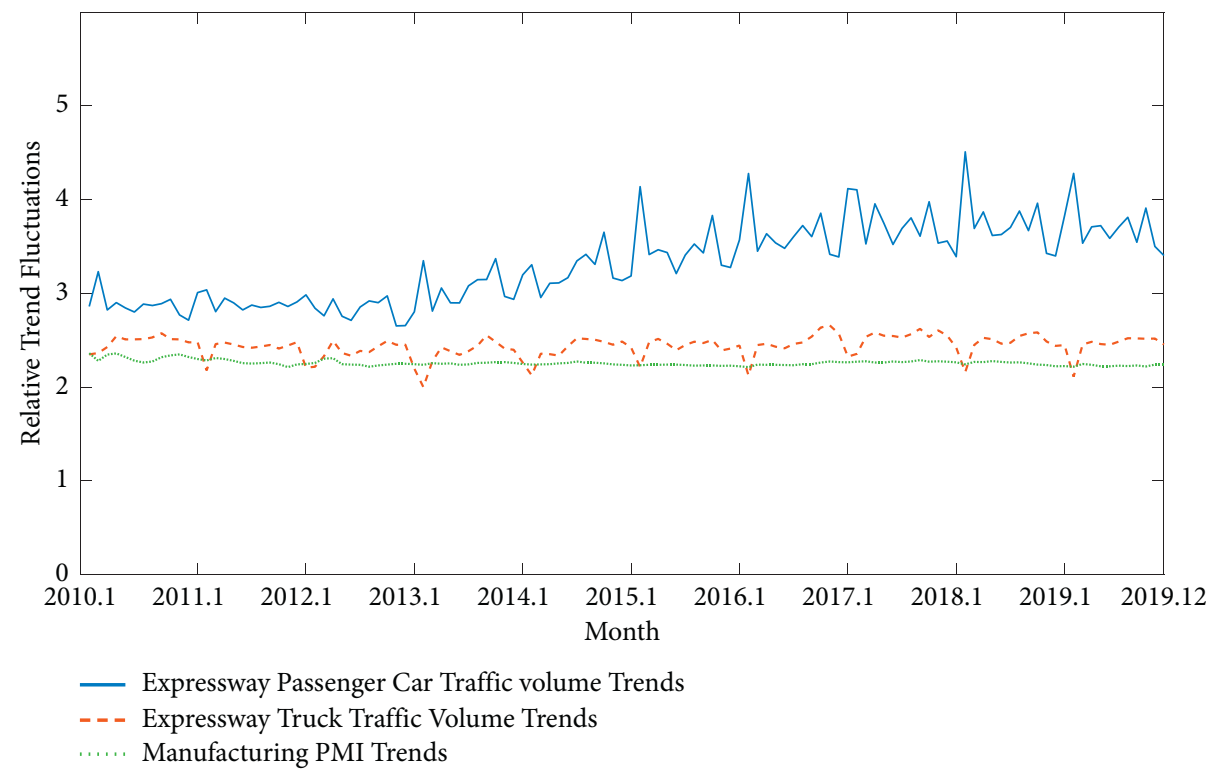

Figure 1: Variation tendency of expressway passenger car and truck traffic volume and manufacturing PMI.

TABLE 1: Unit root test of expressway passenger car, freight traffic, and manufacturing PMI.

\begin{tabular}{lcccc}
\hline Difference order & 5\% level & & \multicolumn{2}{c}{ ADF test results } \\
& & Truck & Manufacturing PMI \\
\hline Level & -1.94 & 2.5944 & -0.3569 & -0.6736 \\
1st difference & -2.89 & -5.9552 & -3.9243 & -12.4554 \\
\hline
\end{tabular}

TABle 2: Cointegration test of expressway passenger car, freight traffic, and manufacturing PMI.

\begin{tabular}{|c|c|c|c|c|c|c|c|}
\hline \multirow{2}{*}{ Hypothesized no. of CE (s) } & \multirow{2}{*}{ Eigenvalue } & \multicolumn{3}{|c|}{ Trace } & \multicolumn{3}{|c|}{ Maximum eigenvalue } \\
\hline & & Trace statistic & $5 \%$ critical value & Prob. & Maxeigen statistic & $5 \%$ critical value & Prob. \\
\hline None & 0.3104 & 63.0907 & 29.7971 & 0.0000 & 43.4819 & 21.1316 & 0.0000 \\
\hline At most 1 & 0.1312 & 19.6088 & 15.4947 & 0.0113 & 16.4514 & 14.2646 & 0.0222 \\
\hline At most 2 & 0.0266 & 3.1574 & 3.8415 & 0.0756 & 3.1574 & 3.8415 & 0.0756 \\
\hline
\end{tabular}

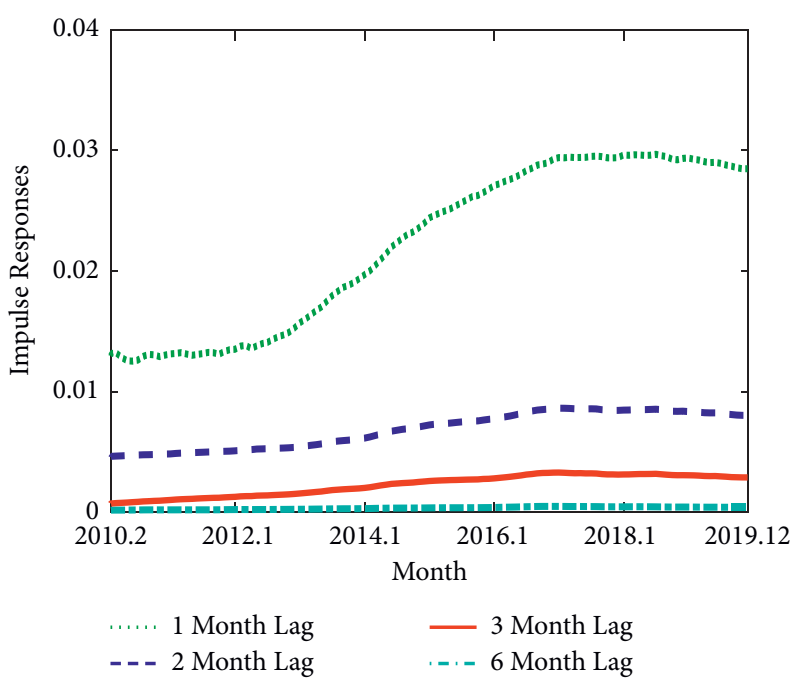

(a)

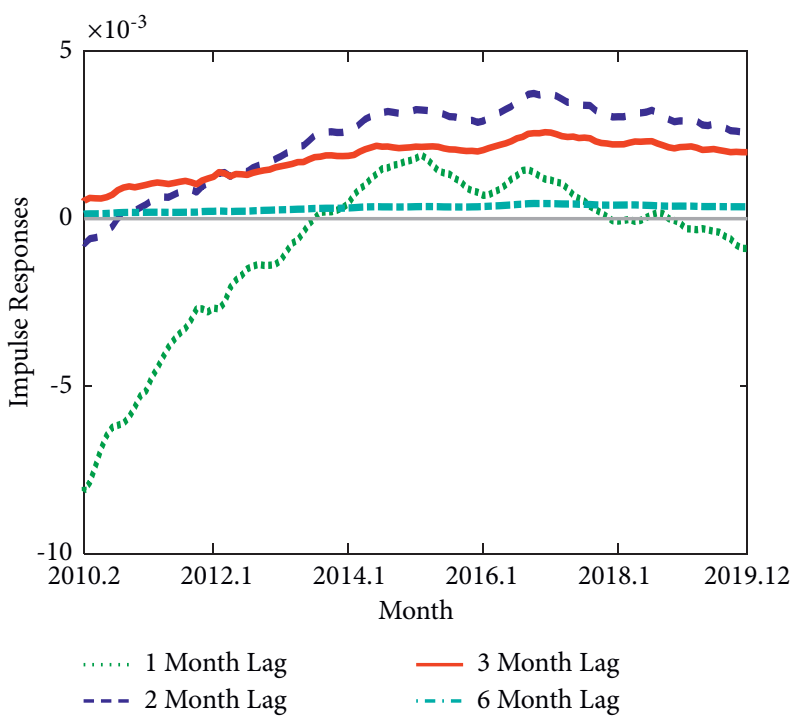

(b)

Figure 2: Continued. 

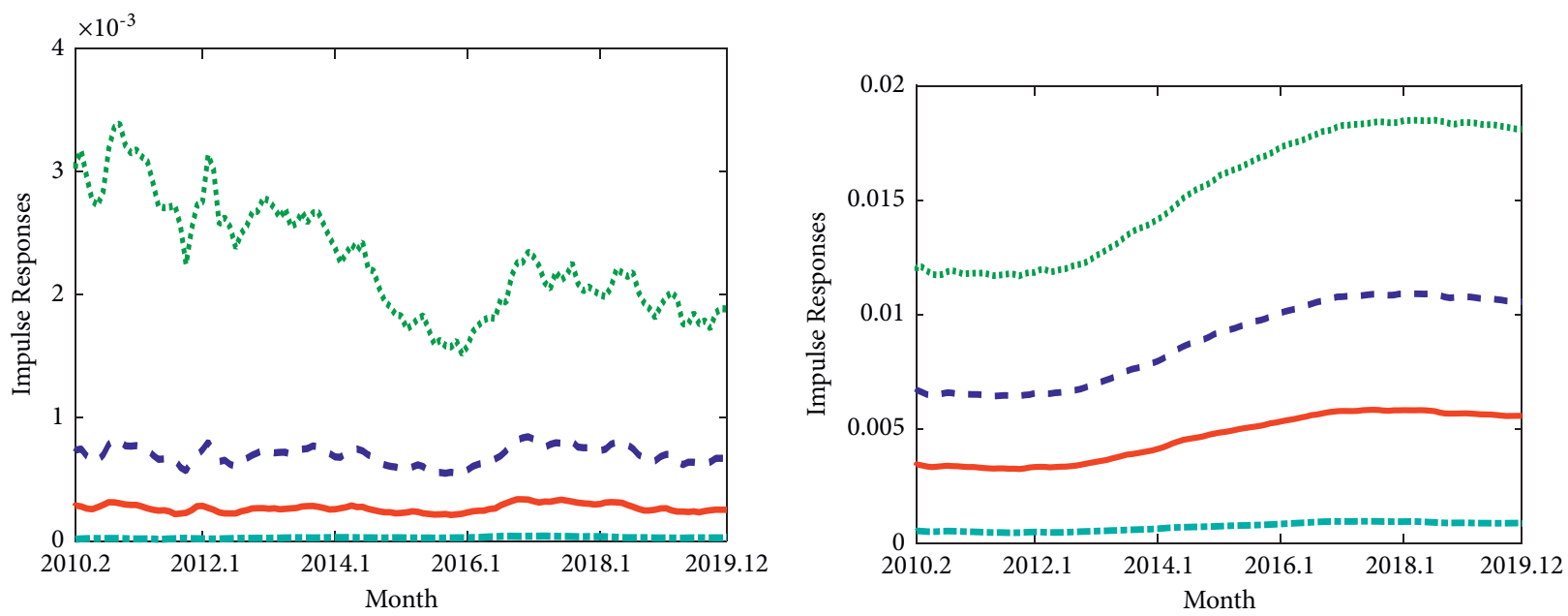

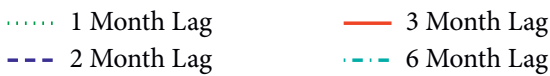

(c)

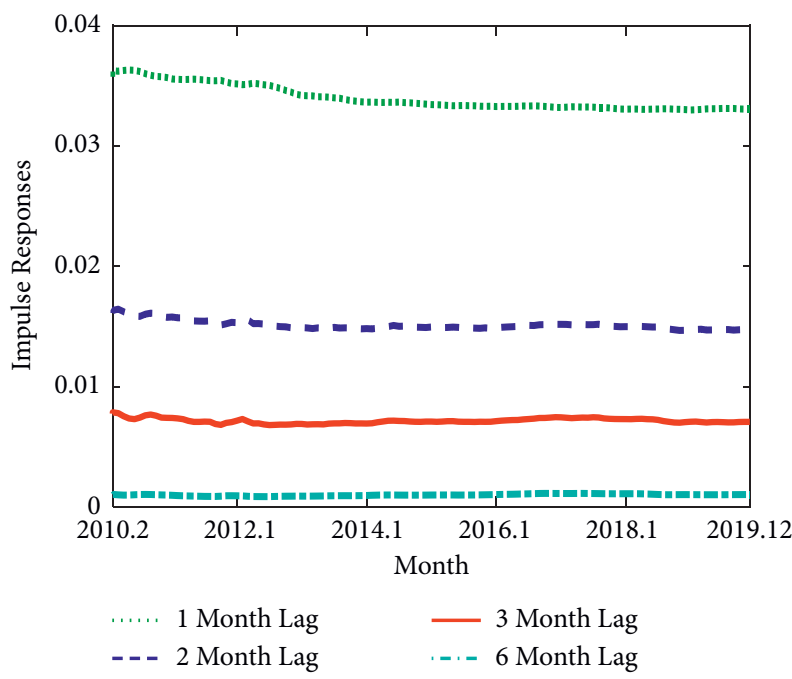

(e)

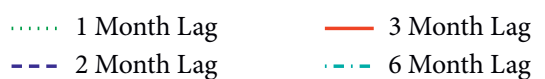

(d)

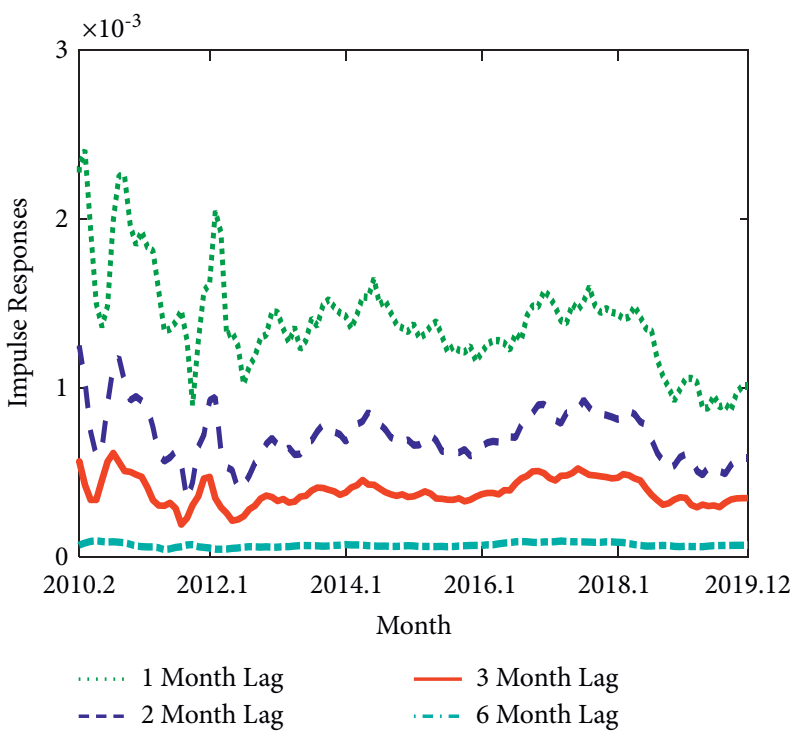

(f)

FIgUre 2: Continued. 


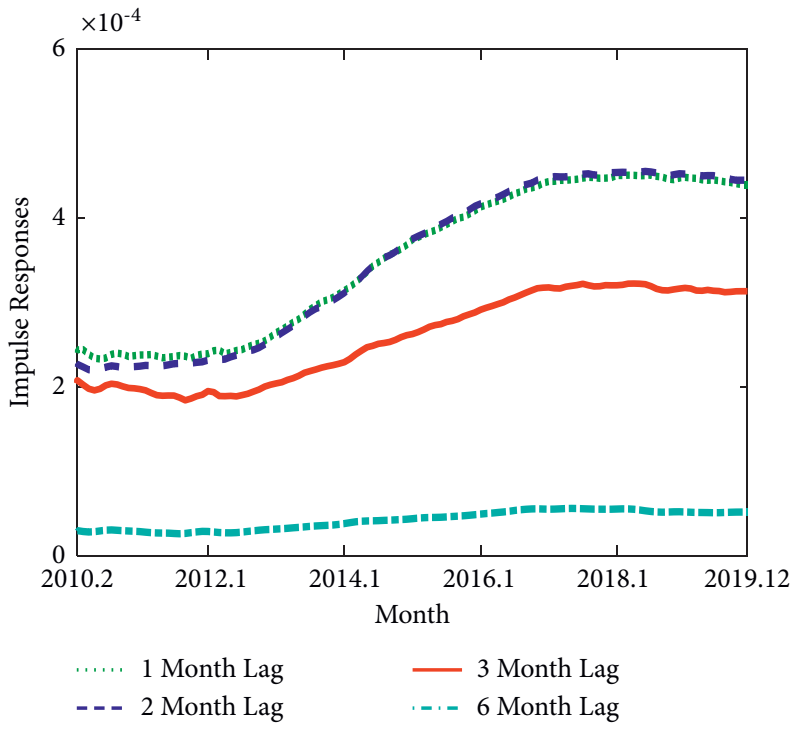

(g)

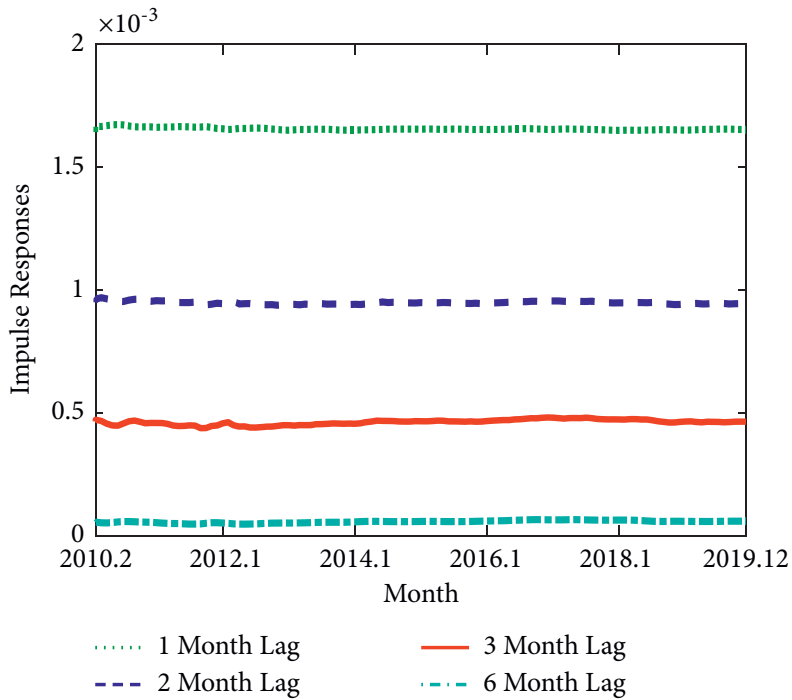

(h)

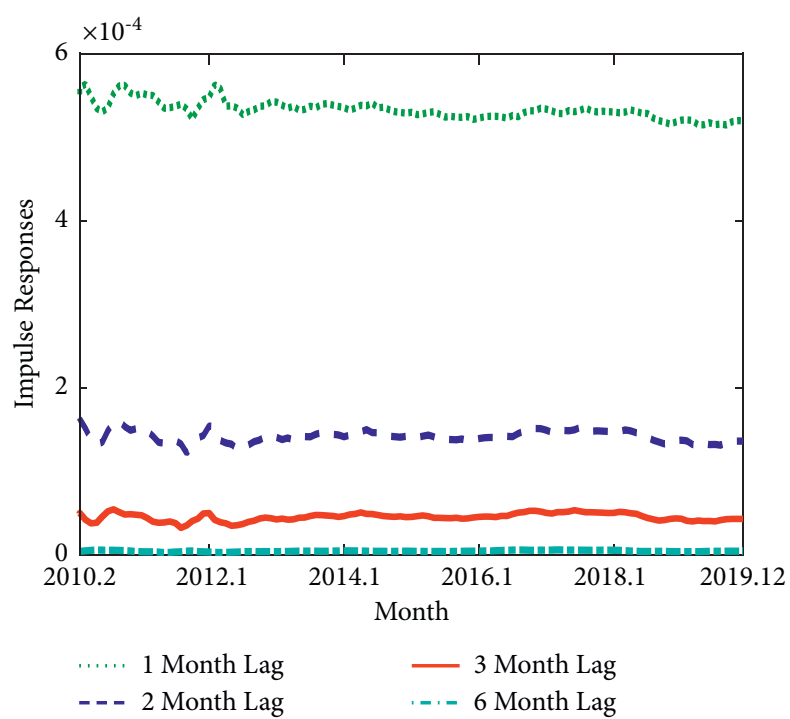

(i)

Figure 2: Time-varying impulse response between traffic volume of expressway passenger cars, traffic volume of trucks, and manufacturing PMI for different lag times. (a) Response C to C. (b) Response T to C. (c) Response P to C. (d) Response C to T. (e) Response T to T. (f) Response P to T. (g) Response C to P. (h) Response T to P. (i) Response P to P.

on truck traffic volume. The mutual relationship between the three variables is discussed below.

The response of $\mathrm{P}$ to $\mathrm{C}$ in Figure 2(c) has been positive for ten years, suggesting that expressway passenger car traffic volume has a positive impact on manufacturing PMI for a long time. For example, an increase in passenger car traffic volume on expressways will promote the development of manufacturing. Longitudinal analysis shows that the impact is highest when the lag is 1 month. As the time lags become larger, the impact gradually decreases and stabilizes. The impact reaches almost zero when the time lag becomes 6 months. The result indicates that the impact of expressway passenger car traffic on manufacturing PMI will gradually weaken as the lag time increases. Horizontal analysis of the impulse response curve shows that the impact of expressway passenger traffic volume on the manufacturing PMI gradually weakened from 2010 to 2015. In 2016, the impact began to rebound to a higher and stable position. Overall, the positive promotion effect is still obvious although the increase in expressway passenger car traffic has a decline promotion effect on the development of manufacturing industry.

Response of $\mathrm{P}$ to $\mathrm{T}$ in Figure 2(f) has also been positive for ten years, suggesting that the increase in truck traffic volume on expressways will promote the development of manufacturing. Longitudinal analysis shows that the impact of expressway truck traffic volume on manufacturing PMI is basically similar to the passenger car traffic volume on 
manufacturing PMI. The impact is highest when the time lag is 1 month, and then, the impact gradually decreases. When the lag enlarged to 6 months, the impulse response curve has been steadily dropped to around 0 , which indicates the situation of no promotion effect. Horizontal analysis shows that fluctuations of impulse response curves for lags of 1 month, 2 months, and 3 months are quite similar. Different from passenger car traffic volume, the impact of truck traffic volume on manufacturing PMI has dropped significantly after 2018 due to the impact of transportation structure reform policies, e.g., "revolution to rail and water to revolution."

Response of $\mathrm{C}$ to $\mathrm{P}$ in Figure 2(g) shows a positive impact of manufacturing PMI on expressway passenger car traffic volume. That is, the increase in manufacturing PMI will reversely stimulate the increase in expressway passenger car traffic volume. For lags of 1 month and 2 months, sizes of the impulse response curve are basically the same. The reduction in impulse response is smaller when the lag is 3 months. The impulse response of manufacturing PMI to expressway passenger car traffic volume has gradually increased since 2012. The figure further shows the following. (1) The development of manufacturing industry will reversely stimulate the increase of expressway passenger car traffic, and the stimulus lasts for a long time. The stable impact is about 2 months. (2) In recent years, the development of manufacturing industry has gradually stimulated expressway passenger car traffic volume. The convenient and fast travel conditions provided by expressways make the role of "traffic first" stand out.

Response of T to $\mathrm{P}$ in Figure 2(h) shows a stable and an almost constant impulse response. As the lag increases, the increase in manufacturing PMI has significantly reduced the stimulus effect on expressway truck traffic volume. Such result means the development of manufacturing industry will promote the increase of expressway truck traffic volume. However, this promotion will not be affected by the degree of manufacturing development.

\section{Conclusions}

In this paper, the TVP-VAR model is applied to explore the time-varying interaction relationship among the three variables of expressway passenger car and truck traffic volume and manufacturing PMI. The results can help policy makers to better understand the mutual reinforcing relationship between China's Expressway traffic volume and manufacturing economy. Based on the mutual relationship, in-depth suggestions can be given to the development of China's transportation and new infrastructure construction. The results can also allow government to make corresponding policy measures for different development opportunities. Furthermore, this research is helpful for the understanding the role of free expressway pass policy in promoting the economic recovery of manufacturing industry during COVID-19.

Specifically, this article starts with China's expressway passenger car, truck traffic volume, and manufacturing PMI index data from 2010 to 2019. The TVP-VAR model is applied to analyze the time-varying interaction between the three variables. The result shows that there is a long-term and stable interaction between the traffic volume of passenger cars and trucks on expressway and the manufacturing PMI in China. And, the interaction relationship is asymmetric. The increased traffic volume during COVID-19 freeway period is of great significance to the resumption of work and production in China. Other conclusions are briefly discussed as follows:

(1) There is a long-term positive interaction between expressway passenger car and truck traffic volume and manufacturing PMI. The increase in passenger car and truck traffic volume on expressways will promote the development of manufacturing. In turn, the development of manufacturing industry will also increase expressway traffic volume. This mutual promotion has a strong influence within 1 month. However, no interaction impact is shown for half-year lag.

(2) The increase in expressway passenger car traffic volume has continued to stimulate the development of manufacturing industry at a high level. The increase in the number of tourist trips is still significant in promoting the manufacturing economy. At the same time, under the influence of freight structure adjustment policies, the promotion of the development of manufacturing industry by expressway truck traffic volume has declined after 2018. The implementation effect of road transport structure adjustment policy is remarkable.

(3) In recent years, the stimulus effect of the development of manufacturing industry on expressway passenger car traffic volume has gradually increased. The economic development model led by domestic demand has gradually been ineffective. Domestic demand has gradually become the main driving force, development orientation, and support for economic growth. However, the stimulus effect of the development of manufacturing on expressway truck traffic has remained basically unchanged in past decade. That is, the structure of road freight transportation in China is relatively stable and reliable, and it is less affected by policy factors.

This article has some limitations. This article only considers the interaction between expressway passenger car and truck traffic volume and manufacturing PMI. Other relevant factors in the operation of expressways, including road network mileage, road congestion, and adaptive traffic volume, are ignored. However, considering these factors can give a much more complete and detailed understanding of the promotion effect of various indicators in the development of expressways on manufacturing economy, in future research, we will try to improve it.

\section{Data Availability}

The data on the traffic volume of passenger cars and trucks were collected by China National Traffic Survey Data Collection System, so they are not free. Requests for access to 
these data should be made to the corresponding author (sunshuo@tpri.org.cn). The data on manufacturing PMI were collected by China National Bureau of Statistics. People can get these data from the official website.

\section{Conflicts of Interest}

The authors declare that they have no conflicts of interest.

\section{References}

[1] P. Li, "The influence of expressway on social and economic development," China's Foreign Trade, vol. 6, pp. 59-61, 2011.

[2] S. Kim, Z. Zafari, M. Bellanger, and P. A. Muennig, "Costeffectiveness of capping freeways for use as parks: the New York cross-bronx expressway case study," American Journal of Public Health, vol. 108, no. 3, pp. 379-384, 2018.

[3] R. M. Xiao, B. Li, and Y. S. Chen, "Transportation status of Chinese expressway network in 2013," Journal of Traffic and Transportation Engineering, vol. 14, pp. 67-73, 2014.

[4] X. N. Long and X. Gao, "Transportation infrastructure and productivity of manufacturing firmseevidence from countylevel expressway data and Chinese industrial enterprises database," Journal of Huazhong Normal University(Humanities and Social Sciences), vol. 53, pp. 43-52, 2014.

[5] O. Kalan and I. Gokasar, "A dynamic panel data approach for the analysis of the growth impact of highway infrastructures on economic development," Modern Economy, vol. 11, no. 03, pp. 726-739, 2020.

[6] J. B. Mills and J. D. Fricker, "Spatial panel econometric analysis of economic impacts of bypasses," Transportation Research Record: Journal of the Transportation Research Board, vol. 2242, no. 1, pp. 122-133, 2011.

[7] Y. H. Ji and J. Wen, "Research on the influence of transportation infrastructure on manufacturing agglomeration in China," Development and Research, vol. 10, pp. 39-43, 2016.

[8] W. P. Bai, Z. Lu, and L. P. Liu, "Foreign direct Investment, Transportation infrastructure improvement and manufacturing agglomeration -- empirical research on panel data of 285 cities in China from 2003 to 2016," Journal of Guizhou University of Finance and Economics, vol. 199, pp. 16-28, 2019.

[9] P. N. Patatoukas and A. Skabardonis, "Traffic volume and aggregate economic activity: implications for taking the pulse of the U.S. Economy. Transportation research record," Journal of the Transportation Research Board, 2016.

[10] N. Caceres, L. M. Romero, F. J. Morales, A. Reyes, and F. G. Benitez, "Estimating traffic volumes on intercity road locations using roadway attributes, socioeconomic features and other work-related activity characteristics," Transportation, vol. 45, no. 5, pp. 1449-1473, 2018.

[11] H. Xiong and Y. W. Sun, "Analysis of Co-integration and causality between freight traffic volume and economic growth in China," Systems Engineering, vol. 28, pp. 50-54, 2010.

[12] A. M. Sha, "Discussion on countermeasures and intelligent operation mode of division construction for the expressway passenger and freight transport system," China Journal of Highway and Transport, vol. 33, pp. 1-7, 2020.

[13] B. B. Yan, Application of Sign Restriction on TVP-VAR Model in Loan Supply and Demand Shocks in China, Huazhong University, Huazhong, China, 2013.

[14] C. A. Sims, "Macroeconomics and reality," Econometrica, vol. 48, no. 1, pp. 1-48, 1980.
[15] O. Blanchard and M. Watson, Are Business Cycles All Alike?, University of Chicago Press, Chicago, IL, USA, 1986.

[16] G. E. Primiceri and E. Giorgio, "Time varying structural vector autoregressions and monetary policy," The Review of Economic Studies, vol. 72, no. 3, pp. 821-852, 2005.

[17] J. Nakajima, M. Kasuya, and T. Watanabe, "Bayesian analysis of time-varying parameter vector autoregressive model for the Japanese economy and monetary policy," Journal of the Japanese and International Economies, vol. 25, no. 3, pp. 225-245, 2011.

[18] B. Pfaff, "VAR, SVAR and SVEC models: implementation within R package vars," Stat. Softw, vol. 27, pp. 1-32, 2008.

[19] R. F. Engle and M. W. Watson, "The kalman filter model: applications to forecasting and rational expectations," Advances in Econometrics: Fifth World Congress of Econometric Society, vol. 1, pp. 245-283, 1987.

[20] G. Koop and D. Korobilis, "Bayesian multivariate time series methods for empirical macroeconomics," Foundations and Trends(R) in Econometrics, vol. 3, 2010.

[21] W. Y. Yap and J. S. L. Lam, "Competition dynamics between container ports in east asia," Transportation Research Part A: Policy and Practice, vol. 40, no. 1, pp. 35-51, 2006.

[22] S. Johansen, "Statistical analysis of cointegration vectors," Journal of Economic Dynamics and Control, vol. 12, no. 2-3, pp. 231-254, 1998. 